\title{
Effect of Predator-Prey Phylogenetic Similarity on the Fitness Consequences of Predation: A Trade-off between Nutrition and Disease?
}

\author{
David W. Pfennig
}

Department of Biology, University of North Carolina, Chapel Hill, North Carolina 27599

Submitted April 1, 1999; Accepted October 7, 1999 as a function of phylogenetic similarity between predator and prey, where phylogenetic similarity refers to the degree to which different populations or species have identical allele frequencies (Nei 1987).

A potentially important benefit of predation that may vary with predator-prey phylogenetic similarity is prey nutritional quality. In general, predators experience enhanced growth and development by eating phylogenetically similar prey. Presumably, such prey are "prepackaged" with the proper proportions of materials necessary for the predator's growth, maintenance, and reproduction (Meffe and Crump 1987; Crump 1990, 1992). Indeed, animals fed on conspecifics often grow better than those fed on heterospecifics. For example, Japanese toad tadpoles (Bufo vulgaris) that are fed conspecifics convert amino acids more efficiently than do tadpoles fed an artificial food or a fishmeal diet (Nagai et al. 1971), and individuals fed conspecifics grow larger than those fed heterospecifics in mosquitofish (Gambusia affinis; Meffe and Crump 1987), treefrog tadpoles (Hyla pseudopuma; Crump 1990), and larval long-toed salamanders (Ambystoma macrodactylum; Wildy et al. 1998).

Such nutritional benefits of feeding on phylogenetically similar prey apply not only when contrasting conspecific prey to heterospecific prey but also when comparing heterospecific prey of varying phylogenetic similarity to the predator. The nutritional benefits of predation may decrease with decreasing phylogenetic similarity between predator and prey because phylogenetically distant prey may lack the necessary nutrients to sustain predator growth. For example, carabid beetles (Agonum dorsale) produce more eggs when fed other arthropods (aphids and flies) than when fed annelids (Bilde and Toft 1994), and fish (Japanese flounder and seabream) grow better when fed other species of fish than when fed poultry or beef (Kikuchi et al. 1997; Nengas et al. 1999). Thus, feeding on phylogenetically similar prey may be a critical means of attaining nutrients that might otherwise be unavailable or difficult to obtain. 
Detracting from the nutritional benefits of feeding on phylogenetically similar prey is an enhanced risk of acquiring from such prey disease-causing parasites (e.g., bacteria, fungi, parasitic helminths, prions, protozoa, viruses). Many parasites are transmitted through ingestion of infected tissue (reviewed in Lozano 1991). Moreover, contagions are often more highly transmissible among phylogenetically similar individuals than among phylogenetically dissimilar individuals (Barbehenn 1969; Freeland 1983). For example, cannibalistic tiger salamanders (Ambystoma tigrinum) are more likely to acquire parasites from conspecifics than from similarly infected heterospecifics (Ambystoma texanum; Pfennig et al. 1998). Presumably, pathogens are more transmissible among phylogenetically similar hosts because there is often strong selection for host specificity and resistance to host immune defenses among parasites. Yet as hosts become less similar, they typically are less likely to share key cellular and molecular features (e.g., cell surface receptors, enzymes, growth factors) to which a single parasite could adapt. Thus, there is generally a declining probability as old and new hosts become less similar phylogenetically that a parasite will survive in a new host.

The declining risk of pathogen transmission with decreasing phylogenetic similarity between hosts applies to many orally transmitted parasites. For instance, although kuru (a fatal prion disease transmitted through cannibalism in humans) has been successfully transmitted by feeding infected tissue to various primate species as well as mink and ferret (Gibbs et al. 1980), dozens of other (nonprimate) mammalian and avian species have been inoculated without their developing the disease, even after many years of observation (Gajdusek 1977). Moreover, bovine spongiform encephalopathy (BSE) was likely derived from scrapie prions that were transmitted to cattle after they were fed tissue from infected ruminants (Prusiner 1998). Scrapie and BSE have been successfully transmitted only to mammals (Gibbs et al. 1980; Fraser et al. 1992; Baker et al. 1993; Foster et al. 1994). Furthermore, meat eaters generally are more likely to obtain harmful parasites from their food than are non-meat-eaters (Hegner 1924), and humans who eat mammals are at greater risk of parasites than those who eat fish, reptiles, or birds (e.g., Debyser and Zwart 1991; Kelly et al. 1995; Huchzermeyer 1997). Indeed, ingestion of other mammals (especially primates) appears to be the ultimate source in human populations of certain highly virulent retroviral pathogens (Koralnik et al. 1994; Voevodin et al. 1997; Gao et al. 1999) and prion diseases (Alpers 1987; Berger et al. 1997; Bruce et al. 1997; Hill et al. 1997).

Given that both the risk of parasite transmission and the nutritional quality of prey may generally decline with decreasing phylogenetic similarity between predator and prey, how do these two factors interact to shape the evolution of diet choice in animals? One possibility is that the increased nutritional benefit derived from eating phylogenetically similar prey offsets the increased risk of pathogen transmission. Thus, the optimal prey might often be those of intermediate phylogenetic similarity to the predator (fig. 1).

I sought to measure experimentally the fitness consequences of predation as a function of phylogenetic similarity between predator and prey. I used as predators three sympatric species of tadpoles. Prey consisted of four tadpole species and anostracan fairy shrimp; parasites were naturally occurring bacteria. To estimate costs and benefits of predation, I measured predator survival and growth. Larval growth correlates with components of adult fitness (Pfennig et al. 1991a) and is sensitive to both prey nutritional quality (Pfennig et al. 1991a) and prey pathogen load (Pfennig et al. 1998).

This study addressed two questions: Do the fitness consequences of predation vary with phylogenetic similarity between predator and prey, and if so, why? And when given a choice among phylogenetically diverse prey, which prey do predators preferentially consume?

\section{Methods}

Study Animals

Plains spadefoot toads (Spea bombifrons), southern spadefoot toads (Spea multiplicata), Couch's spadefoot toads (Scaphiopus couchii), and great plains toads (Bufo cognatus) co-occur in the southwestern United States and northern

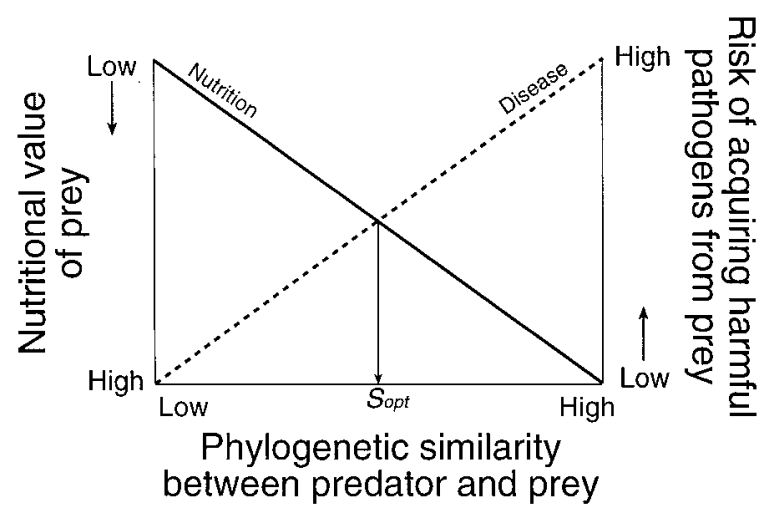

Figure 1: Hypothesized effects of predator-prey phylogenetic similarity on nutritional value of prey (solid curve) and risk that the predator will acquire deleterious pathogens from prey (dashed curve). If increased nutritional benefits of feeding on phylogenetically similar prey offset increased costs of disease transmission between predators and phylogenetically similar prey, then prey of intermediate phylogenetic similarity may provide greatest fitness benefits to predators $\left(S_{\text {opt }}\right)$. 
Table 1: Relationship between predator-prey genetic similarity and growth and survival of tadpole predators

\begin{tabular}{|c|c|c|c|}
\hline Predator/prey & $\begin{array}{c}\text { Genetic similarity (Nei's) } \\
\text { between predator } \\
\text { and prey } \\
(\bar{X} \pm \mathrm{SD})\end{array}$ & $\begin{array}{c}\text { Growth rate } \\
(\bar{X} \pm \mathrm{SD})\end{array}$ & $\begin{array}{l}\text { Percentage of } \\
\text { predators } \\
\text { that survived }\end{array}$ \\
\hline \multicolumn{4}{|l|}{ Spea bombifrons: } \\
\hline S. bombifrons & 1.0 & $.09 \pm .02^{\mathrm{A}}$ & 95 \\
\hline Spea multiplicata & $.58 \pm .02$ & $.09 \pm .02^{\mathrm{A}}$ & 95 \\
\hline Scaphiopus couchii & $.41 \pm .01$ & $.10 \pm .02^{\mathrm{B}}$ & 100 \\
\hline Anostracans & 0 & $.06 \pm .02^{\mathrm{C}}$ & 95 \\
\hline \multicolumn{4}{|l|}{ S. multiplicata: } \\
\hline S. multiplicata & 1.0 & $.11 \pm .01^{\mathrm{A}}$ & 100 \\
\hline S. bombifrons & $.58 \pm .02$ & $.11 \pm .02^{\mathrm{A}}$ & 95 \\
\hline S. couchii & $.34 \pm .02$ & $.13 \pm .01^{\mathrm{B}}$ & 100 \\
\hline Anostracans & 0 & $.06 \pm .02^{\mathrm{C}}$ & 95 \\
\hline \multicolumn{4}{|l|}{ S. couchii: } \\
\hline S. couchii & 1.0 & $.08 \pm .01^{\mathrm{A}}$ & 80 \\
\hline S. bombifrons & $.41 \pm .01$ & $.09 \pm .01^{\mathrm{A}}$ & 96 \\
\hline S. multiplicata & $.34 \pm .02$ & $.10 \pm .01^{\mathrm{B}}$ & 84 \\
\hline Bufo cognatus & .15 & $.08 \pm .02^{\mathrm{A}}$ & 80 \\
\hline
\end{tabular}

Note: Mean growth rate values with different letters within each species were significantly different at $P<.05$ (Fisher's protected least significant difference test).

Mexico (Stebbins 1985). All four species often breed in the same rain-filled pools, where their tadpoles feed on organic detritus, algae, small crustaceans (e.g., anostracans), and smaller tadpoles (Pomeroy 1981). In addition, Spea tadpoles display trophic polyphenism. Following ingestion of anostracans or tadpoles, typically omnivorous tadpoles may alter behavioral and morphological development to assume a carnivore phenotype (Pfennig 1992). These carnivore-morph tadpoles, which experience accelerated development, feed primarily on fairy shrimp and other tadpoles.

I studied S. bombifrons, S. multiplicata, and S. couchii from nine sibships each and B. cognatus from three sibships. The parents of all four species were captured from two ponds near Apache, Arizona $\left(31^{\circ} 40^{\prime} \mathrm{N}, 109^{\circ} 08^{\prime} \mathrm{W}\right)$. After hatching, the tadpoles from different sibships were reared in separate aquaria filled with $15 \mathrm{~L}$ of dechlorinated water. All tadpoles were reared under identical conditions and fed rabbit chow daily ad lib. during rearing until they were used in the experiments outlined below.

\section{Estimation of Phylogenetic Similarity between Predator and Prey}

To estimate phylogenetic similarity between predators and their prey, I used Nei's (1987) genetic similarity index. This index measures the degree to which different populations or species have identical allele frequencies. Genetic similarities among the three spadefoot species have been estimated from allozyme markers by Sattler (1980) and are given in table 1. Genetic similarities between S. couchii and B. cognatus and between the two Spea species and anostracans, also given in table 1 , were estimated based on values from other taxa that were judged to be similarly diverged.

\section{Prey Preparation and Bacterial Assays}

To create the prey used in Experiment 1, I randomly selected about 800 tadpoles of S. bombifrons, S. multiplicata, S. couchii, and B. cognatus, which differed from each other in snout-vent length by no more than $5 \%$ and were of Gosner (1960) developmental stages 26-28. Live tadpoles of each species were put into a separate pan and placed in a freezer for $1 \mathrm{~h}\left(\right.$ at ca. $\left.-2^{\circ} \mathrm{C}\right)$. The tadpoles were then dried in an oven at $50^{\circ} \mathrm{C}$ for $48 \mathrm{~h}$. I also placed a large mass of live, field-collected anostracans (Streptocephalus spp.) in a freezer for $1 \mathrm{~h}$ and then dried them in an oven at $50^{\circ} \mathrm{C}$ for $48 \mathrm{~h}$. Each type of dried prey was pulverized into small flakes (about $2 \mathrm{~mm}$ in diameter), using a sterile mortar and pestle. Such manipulations probably did not alter nutritional content of prey (Crump 1990).

To determine whether the dried prey contained naturally occurring parasites, I assayed aerobic, Gram-negative bacteria. Such bacteria are generally indicative of overall pathogen levels in natural amphibian communities (Worthylake and Hovingh 1989; Pfennig et al. 1991b). I sprinkled $0.035 \mathrm{~g}$ of each prey type on $90-\mathrm{mm}$ plates containing 
Emb agar and incubated the plates at $37^{\circ} \mathrm{C}$ for $24 \mathrm{~h}$. I anticipated finding numerous bacterial colonies because tadpoles raised in the laboratory often contain pathogenic Clostridium and Aeromonas bacteria (D. Pfennig, personal observation). Moreover, many pathogens can withstand freezing, low heat, and desiccation (e.g., Clostridium bacteria produce a special reproductive structure called the endospore, which is highly resistant to environmental stress).

\section{Experiment 1: Effect of Predator-Prey Phylogenetic Similarity on the Fitness Consequences of Predation}

In the first phase of this experiment, I randomly assigned 80 7-d-old omnivore-morph S. bombifrons tadpoles and 80 7-d-old omnivore-morph S. multiplicata tadpoles (Gosner [1960] stages 31-34) to one of four treatment groups, which differed in the type of prey the focal tadpole received. Each tadpole was placed into a separate $18 \times$ $28 \times 11-\mathrm{cm}$ plastic tank filled with $5 \mathrm{~L}$ of dechlorinated water. Focal S. bombifrons or S. multiplicata tadpoles were fed exclusively S. bombifrons tadpoles, S. multiplicata tadpoles, S. couchii tadpoles, or anostracan fairy shrimp. Twenty tadpoles from each species (five from each of four sibships) were assigned to each treatment group. Focal tadpoles were initially similar to each other in wet mass

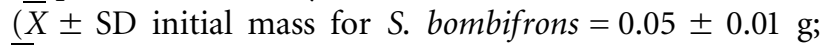
$\bar{X} \pm \mathrm{SD}$ initial mass for $S$. multiplicata $=0.03 \pm 0.01 \mathrm{~g}$; there were no significant differences across treatments for S. bombifrons [ANOVA: $F=0.21, \mathrm{df}=3,79, \mathrm{NS}$ ] or for $S$. multiplicata [ANOVA: $F=0.19, \mathrm{df}=3,79, \mathrm{NS}]$ ). Each focal tadpole was given $0.035 \mathrm{~g}$ of prey on day 1 (equivalent to about 100 live tadpoles). By day 8, all focal tadpoles had eaten their first ration of food (the disappearance of flakes could be monitored easily). Thus, on day 8, each focal tadpole was fed another $0.035 \mathrm{~g}$ of prey. By day 15, all food had again disappeared from the tanks. The experiment was terminated on day 15 , at which time wet mass of each focal tadpole was recorded. Response variables were predator survival and growth rate. In this and all other experiments, growth rate was calculated as $(\ln$ [final mass] $-\ln$ [initial mass])/time, which is independent of initial size.

In the second phase of the experiment, I randomly assigned 100 7-d-old S. couchii tadpoles (Gosner [1960] stages 32-34) to one of four treatment groups, which differed in the type of prey focal tadpoles received. Each tadpole was placed into a separate $18 \times 28 \times 11$-cm plastic tank filled with $5 \mathrm{~L}$ of dechlorinated water. Focal $S$. couchii tadpoles were fed exclusively on tadpoles of S. bombifrons, S. multiplicata, S. couchii, or B. cognatus. Twentyfive tadpoles (five from each of five sibships) were assigned to each treatment group. There were significant differences across treatments in initial wet mass (ANOVA: $F=3.15$, $\mathrm{df}=3,99, P=.03$ ). Each focal tadpole was given $0.035 \mathrm{~g}$ of prey four times: once each on day 1 , day 8 , day 13 , and day 22 (all tadpoles had eaten their previous ration of food before subsequent feedings). The experiment was terminated on day 26 , at which time wet mass of each focal tadpole was recorded. As before, response variables were predator survival and growth rate.

\section{Experiment 2: Effects of Prey Pathogen Load and Predator-Prey Phylogenetic Similarity on the Fitness Consequences of Predation}

I sought to determine whether a cost of preying on phylogenetically similar prey is increased risk of acquiring deleterious parasites. I specifically sought to establish whether tadpoles had significantly lower survival and growth rates when fed diseased conspecifics than when fed diseased noncongeneric tadpoles.

I placed each of 4020 -d-old $S$. couchii tadpoles into a separate $18 \times 28 \times 11-\mathrm{cm}$ plastic tank filled with $5 \mathrm{~L}$ of dechlorinated water. I randomly assigned each tadpole to one of four treatment groups (20 tadpoles/group), which differed in the type of prey the focal tadpole received. Focal $S$. couchii tadpoles were fed exclusively on S. couchii tadpoles with low pathogen loads, S. multiplicata tadpoles with low pathogen loads, $S$. couchii tadpoles with high pathogen loads, and S. multiplicata tadpoles with high pathogen loads. Low-pathogen-load prey were created using the prey preparation procedures outlined above. Highpathogen-load prey were treated the same as low pathogen prey, except high-pathogen-load tadpoles were kept for 24 $\mathrm{h}$ in water from a naturally occurring pond that contained high levels of bacteria and other pathogens. Focal tadpoles were initially similar to each other in wet mass $(\bar{X} \pm \mathrm{SD}$ initial mass $=0.07 \pm 0.02 \mathrm{~g}$; there were no significant differences across treatments: $F=1.58, \mathrm{df}=3,36$, NS). Each focal tadpole was given $0.05 \mathrm{~g}$ of prey on day 1 . The experiment was terminated on day 5 (when all food had been consumed), and the wet mass of each focal tadpole was recorded. Because all focal tadpoles survived the experiment, the response measure was predator growth rate.

\section{Experiment 3: Prey Choice Tests}

The goal of this experiment was to determine which prey species predators would preferentially consume when given a choice among phylogenetically diverse prey. I tested prey preferences of focal carnivorous-morph plains spadefoot toad tadpoles ( $S$. bombifrons) and southern spadefoot toad tadpoles (S. multiplicata) 2-5 wk after they had 


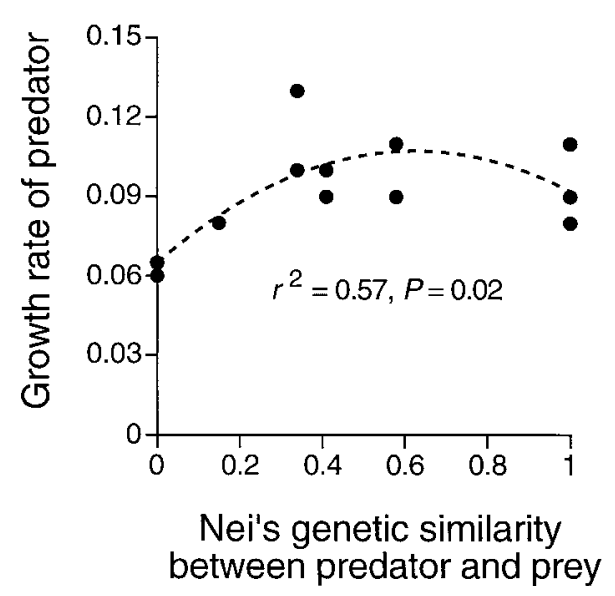

Figure 2: Mean growth rates of three different tadpole predator species as a function of mean predator-prey genetic similarity (growth rates and genetic similarities are from table 1). The dashed line gives the secondorder polynomial regression.

hatched (Gosner [1960] developmental stages 34-36). These focal carnivores had been reared since birth with siblings only and had been fed rabbit chow and fairy shrimp ad lib. To start the experiment, I introduced three equal-sized "stimulus" animals (all omnivore-morph larvae) and one "test" animal (a carnivore morph) to an opaque plastic cup $(12 \mathrm{~cm}$ tall $\times 9 \mathrm{~cm}$ diameter $)$ filled with $470 \mathrm{~mL}$ of dechlorinated tap water. Each focal $S$. bombifrons or S. multiplicata tadpole was given a choice of preying on a conspecific tadpole, a congeneric heterospecific tadpole (S. bombifrons or S. multiplicata), or a noncongeneric tadpole (S. couchii). Stimulus tadpoles were from the lower end of the natural size distribution and were about one-third the snout-vent length of test animals. All test animals were similarly satiated at the start of the test (i.e., they were fed shrimp ad lib. immediately before testing).

To keep track of species identities, I stained one-third of the stimulus animals red and one-third blue by placing tadpoles for $12 \mathrm{~h}$ in a $0.00025 \%$ aqueous solution of neutral red or methylene blue (Waldman 1981). The remaining one-third of the stimulus animals were unmarked. To control for effects of the marks on test-animal prey preferences, in one-third of the cups the test animal's conspecific was stained red, in one-third it was stained blue, and in one-third it was unmarked. These marks did not affect larval mortality.

An observer watched each cup continuously after the animals were introduced and noted both when predation had occurred and the species identity of the consumed animal. All trials were allowed to run until all three stimulus animals were eaten. In 12 trials, two stimulus animals were eaten simultaneously; these were excluded from analysis. Animals were each used only once. I tested the prey preferences of $30 \mathrm{~S}$. bombifrons carnivores and $28 \mathrm{~S}$. multiplicata carnivores. For each trial, I ordered each prey type according to when it was eaten (i.e., first $[=1]$, second $[=2]$, or third [=3]). If predation were random with respect to species identity (my null hypothesis), then the mean rank of each prey species across all trials would be 2 $(=[1+2+3] / 3)$. Thus, for each predator species, I used a two-tailed one-sample $t$-test to compare value 2 against the observed rank at which each prey species was consumed. Because tadpoles were confined to small cups, I assumed that any difference in ingestion order was not caused by different species-specific escape responses.

\section{Results}

\section{Experiment 1: Effect of Predator-Prey Genetic Similarity} on the Fitness Consequences of Predation

Bacterial assays revealed numerous naturally occurring bacteria in all five prey types (Spea bombifrons, Spea multiplicata, Scaphiopus couchii, and Bufo cognatus tadpoles and anostracan shrimp). Among the bacteria present was Clostridium spp., which is harmful to larval amphibians (e.g., see Pfennig et al. 1991b).

Predators may be more likely to acquire these parasites from phylogenetically similar prey than from phylogenetically dissimilar prey, as evidenced by the reduced growth rates observed in predators that were fed conspecific versus heterospecific prey. Indeed, there was a significant overall effect of predator-prey phylogenetic similarity on growth rates of omnivorous $S$. bombifrons $(F=21.24, \mathrm{df}=3,75$, $P=.0001), \quad$ S. multiplicata $(F=16.73, \mathrm{df}=3,76, \quad P=$ $.0001)$, and $S$. couchii tadpoles $(F=7.01, \mathrm{df}=4,91, P=$ .0003). Generally, tadpoles had the highest survival on the type of prey that yielded the highest growth rate (table 1).

The prey species resulting in the greatest growth and survival rates differed for different predator species (table 1). Both species of Spea tadpoles had highest growth rate on S. couchii prey, whereas S. couchii tadpoles had highest growth rate on Spea prey. Thus, tadpoles performed best on noncongeneric tadpoles, and the chances of getting this pattern by chance alone was remote $\left(0.016=0.25^{3}\right)$. Indeed, when all three predator species were considered together, tadpoles had the highest growth rate on these phylogenetically intermediate prey (fig. 2; secondorder polynomial regression: $r^{2}=0.57, F=5.94, \mathrm{df}=$ $2,11, P=.02)$. 


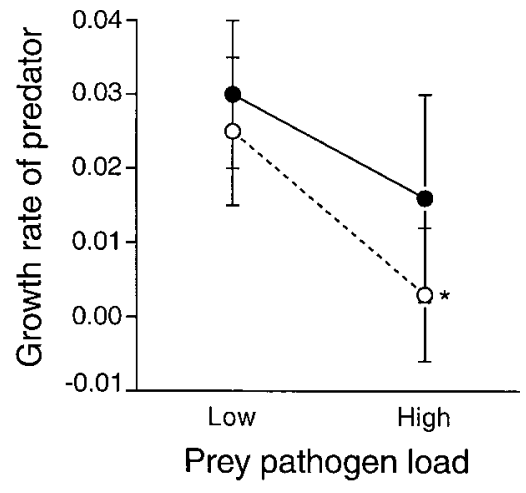

Figure 3: Growth rate $(\bar{X} \pm \mathrm{SD})$ of focal Scaphiopus couchii tadpoles when fed conspecifics (open circles) and noncongeners (filled circles; Spea multiplicata) when each type of prey contained low and high pathogen loads. Asterisk, prey type for which predator growth rate was significantly lower than that for other prey.

\section{Experiment 2: Effects of Prey Pathogen Load and Predator-Prey Phylogenetic Similarity on the Fitness Consequences of Predation}

There was no evidence of a significant interaction effect on predator growth of prey pathogen load and predatorprey phylogenetic similarity $(F=0.06, \mathrm{df}=1,36, \mathrm{NS})$. There were, however, highly significant effects on predator

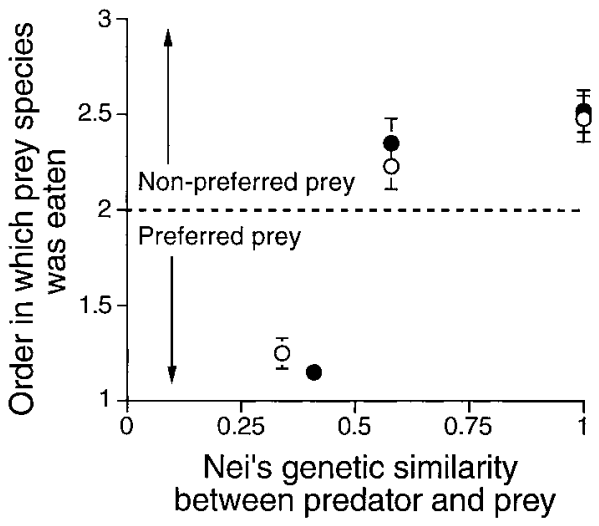

Figure 4: Relationship between mean genetic similarity (Nei's) between two different predator species and their prey and the order in which each prey species was eaten $(X \pm$ SEM). The experiment involved giving focal carnivorous tadpoles (Spea bombifrons [filled circles] and Spea multiplicata [open circles]) a choice of preying on a conspecific tadpole, a congeneric heterospecific tadpole (S. bombifrons or S. multiplicata), or a noncongeneric tadpole (Scaphiopus couchii). The dashed line indicates the value expected (2) if the order in which prey were eaten $(1,2$, or 3$)$ were random with respect to the prey's species identity. Genetic similarity values are from table 1 . growth rate of both prey pathogen load $(F=11.78, \mathrm{df}=$ $1,36, P=.002)$ and predator-prey phylogenetic similarity $(F=5.95, \mathrm{df}=1,36, P=.02)$. Moreover, predators that ate conspecifics containing high pathogen loads grew significantly more slowly than those that ate similarly infected noncongeneric tadpoles with high pathogen loads (Fisher's protected least significant difference test: $P<.05)$. However, none of the other groups differed significantly from each other (fig. 3).

\section{Experiment 3: Prey Choice Tests}

When S. bombifrons and S. multiplicata carnivore-morph tadpoles were offered a choice of eating live S. bombifrons, S. multiplicata, or S. couchii tadpoles, both predator species overwhelmingly preferred to prey on S. couchii (fig. 4). Of 30 S. bombifrons tadpoles tested, $25(83 \%)$ ate S. couchii first, three $(10 \%)$ ate S. multiplicata first, and one $(3 \%)$ ate $S$. bombifrons first (one predator ate both $S$. couchii and S. multiplicata first simultaneously). Of $28 \mathrm{~S}$. multiplicata tadpoles tested, $20(71 \%)$ ate $S$. couchii first, three $(11 \%)$ ate $S$. bombifrons first, and three (11\%) ate S. multiplicata first (two predators ate both $S$. couchii and $S$. bombifrons first simultaneously). Both predator species ate $S$. couchii significantly sooner than expected if predation were random with respect to species identity (fig. 4; $\bar{X} \pm \mathrm{SD}$ order that $S$. couchii was consumed for $S$. bombifrons predators: $1.15 \pm 0.06, t=13.25$, $\mathrm{df}=29$, $P=.0001$; for $S$. multiplicata predators: $1.25 \pm 0.08, t=$ 9.46, $\mathrm{df}=27, P=.0001$; two-tailed one-sample $t$-tests for both).

\section{Discussion}

Tadpoles performed poorly on phylogenetically similar prey and on phylogenetically dissimilar prey (fig. 2), but they probably did so for different reasons. Tadpoles grew significantly less when fed congeneric tadpoles than when fed noncongeneric tadpoles (table 1), perhaps because congenerics were more likely to transmit deleterious parasites to predators. In support of this hypothesis, Scaphiopus couchii predators that ate conspecifics containing high pathogen loads grew significantly more slowly than those that ate similarly infected noncongeneric tadpoles (fig. 3; see also Pfennig et al. 1998). In addition, wildcaught carnivore-morph tadpoles-which often eat conspecifics-typically have higher parasite loads than do noncannibalistic omnivore-morph tadpoles from the same pond (D. Pfennig, personal observation; see also Pfennig et al. 1991b). Tadpoles also grew significantly less when fed phylogenetically distant prey (i.e., Bufo cognatus tadpoles and anostracans) than when fed phylogenetically intermediate tadpoles (table 1). Phylogenetically distant prey 
may have been less likely than phylogenetically intermediate prey to provide nutrients necessary for the predator's growth (Crump 1990).

Thus, the data are consistent with the hypothesis that a trade-off exists between nutrition and disease. In particular, although nutritional quality of prey may decline with decreasing genetic similarity between predator and prey-making less similar prey less nutritious-such prey may also be safer to eat because the chances of acquiring deleterious parasites may also decline with decreasing genetic similarity (fig. 1). Such a trade-off between nutrition and disease is implicated by studies showing that cannibalism is beneficial when parasites are absent (Nagai et al. 1971; Meffe and Crump 1987; Crump 1990; Church and Sherratt 1996; Wildy et al. 1998) but dangerous when parasites are present (Polis 1981; Alpers 1987; Matuschka and Bannert 1989; Schaub et al. 1989; Dhandapani et al. 1993; Boots 1998; Pfennig et al. 1998; Chapman et al. 1999).

A possible alternative explanation for the results is that prey may have differed in fat or energy content, so that some prey species were of generally poor quality. However, this hypothesis does not explain why the prey that yielded greatest growth and survival differed for different predator species. In particular, the differential energy content hypothesis cannot explain why Spea predators grew significantly better on $S$. couchii tadpoles than on Spea tadpoles, whereas $S$. couchii predators grew significantly better on Spea tadpoles than on S. couchii tadpoles.

The effects of other fitness-decrementing factors, such as the presence of toxins in prey, may also vary with phylogenetic similarity between predators and prey and could potentially account for these results. However, because toxins are generally not thought to occur in midstaged tadpoles such as the prey tadpoles used in these experiments (Brodie et al. 1978; Formanowicz and Brodie 1982), they are unlikely to explain the results. Other factors whose effects may vary with phylogenetic similarity between predator and prey include diffusible chemical regulators that inhibit growth rates of other tadpoles (growth inhibitory substances; Licht 1967) and alarm pheromones, which are released when a tadpole is injured (Eibl-Eibesfeldt 1949). Growth inhibitory substances cannot explain these results, however, because these substances generally have a greater inhibitory effect on the growth of heterospecifics than that of conspecifics (Licht 1967), and the opposite pattern was found in these experiments (fig. 2). Alarm substances also appear to be inadequate to explain the results. Although many tadpoles display an enhanced response to alarm substances produced by conspecifics (Richmond 1947), such chemicals cannot explain why tadpoles grew and survived less well on the most phylogenetically distant tadpoles than on tadpoles of intermediate phylogenetic similarity (fig. 2).
In the model presented in figure 1, I have assumed that prey nutritional quality and disease risk both decline monotonically with decreasing phylogenetic similarity between predator and prey. However, all prey less than (or greater than) some critical phylogenetic similarity to a predator might be of similar nutrition and disease risk. Moreover, I have shown the nutrition and disease curves declining at the same rate with decreasing predator-prey phylogenetic similarity. In fact, the slope of the disease curve may be much steeper than that of the nutrition curve for most natural situations. However, even if these details of the curves differ for a given situation from figure 1, this would not alter the key prediction that predators may often perform best on phylogenetically intermediate prey. The optimal similarity ( $S_{\text {opt }}$ in fig. 1 ) would simply shift to higher or lower predator-prey similarity values, depending on where the curves intersect.

Another critical assumption of the model in figure 1 is that prey are afflicted with pathogens that do not have an extremely narrow host range. For example, some pathogens cause disease only in hosts that carry a specific genotype (e.g., Burdon and Jarosz 1988). If prey are afflicted with pathogens that show such an extreme degree of host specificity, and if these pathogens are highly virulent, then selection may favor preferential consumption of phylogenetically similar prey. Phylogenetically similar prey may demonstrate, by being alive, their freedom from lethal highly specific pathogens, whereas live phylogenetically dissimilar prey might secretly harbor such pathogens. Thus, the nutrition-disease trade-off hypothesis may apply only to pathogens that do not have a highly restricted host range. Such generalist pathogens appear to be common in nature (see examples in the introduction). Yet the relative importance of highly specialist pathogens versus generalist pathogens in shaping the evolution of behavior remains unclear.

An important feature to consider regarding the tradeoff between nutrition and disease is the host's immune system. If a predator's immune system "learns" to recognize and destroy parasites in its food, could it not eat parasite-infested food, unencumbered by disease? A predator's immune system may have little effect in mitigating the deleterious consequences of contagions in food. Invertebrates lack acquired immunity, and even in vertebrates the immune system has a relatively short duration memory for certain parasites, such as helminths (Dobson et al. 1992). In addition, there would be no protection against strains or subtypes of parasites to which the host had not been exposed previously. For instance, many pathogens exist as a multitude of strains (e.g., enteroviruses and bacteria such as Salmonella spp.) or are able to alter their antigenic coat (e.g., retroviruses) in response to specific host immunity and thereby evade the immune re- 
sponse (Nokes 1992). Moreover, a number of parasites elude the immune system by remaining hidden in immunologically privileged sites. Finally, no immune system appears to be effective against prion infection: the immune system leaves its own proteins alone, and prion proteins_normal or abnormal-are host proteins (Berg 1994).

An alternative to using phylogenetic similarity to assess disease risk is for predators to detect parasites in prey. If a predator could recognize and avoid infected prey, it might accrue the enhanced nutritional benefits of eating phylogenetically close prey while limiting risks of disease. For instance, bullfrog (Rana catesbeiana) tadpoles avoid conspecifics carrying infectious yeast, Candida humicola, by detecting chemical cues emanating from infected individuals at a distance (Kiesecker et al. 1999). However, because new pathogens arise continually in most populations (Lively 1996), such direct assessment would not be effective during the time lag between when a new pathogen first appears and when the animal first acquires the ability to detect it. Indeed, evolutionary time lags may explain why many predators, such as predatory carabid beetles (Vasconcelos et al. 1996) and tiger salamander larvae (Pfennig et al. 1999), do not discriminate against infected prey. Also, prey often may carry sublethal doses of pathogens that are undetectable and that may bioaccumulate in a predator's tissues over time, leading to disease (Pfennig et al. 1991b). Thus, rather than favoring direct assessment of prey parasite load, natural selection might favor predators that appraise the risk of disease indirectly by assessing their phylogenetic similarity to potential prey. Such an ability to detect phylogenetic similarity is probably commonplace in animals (e.g., see fig. 4), given that many species possess the sensory and neural mechanisms to evaluate genetic similarity (Sherman et al. 1997).

The nutrition-disease trade-off is likely not the only factor contributing to the evolution of diet choice in animals. Trade-offs between selecting more nutritious prey and risking disease will be mediated by other factors, such as the availability of alternative foods, prey handling time, and the risk of predation or injury during feeding. Moreover, predators should be sensitive to how nutritional benefits and disease risk change as the predator's own physical condition and ecological circumstances change. For example, cannibalism in nature appears most frequently in populations and life stages that occur in rapidly deteriorating environments in which alternative prey are scarce (Polis 1981; Crump 1990, 1992; Elgar and Crespi 1992). In such environments, the benefits of rapid growth brought on by cannibalism probably exceed the risks of disease (Pfennig et al. 1998). Thus, prey choice may reflect an optimal balance of all the factors described above, in- cluding the postulated trade-off between nutrition and disease.

The predictions of the nutrition-disease trade-off hypothesis appear to be met in at least one other system. Toft and Wise (1999) fed predatory wolf spiders (genus Schizocosa) five different (nontoxic) arthropod prey: conspecific spiderlings, springtails (Collembola: Tomocerus bidentatus), aphids (Hemiptera: Aphis nerii), gnats (Diptera: Bradysia spp.), and fruit flies (Diptera: Drosophila melanogaster). Although the phylogeny of arthropods is controversial, most classifications place spiders closer to springtails than to insects (e.g., Daly et al. 1998). This hypothesized phylogenetic relationship is significant because predatory spiders have the greatest growth and survival on springtail prey (Toft and Wise 1999). Although it is unclear if springtail prey enable predatory spiders to strike an optimal balance between nutrition and disease risk, these data are consistent with the nutrition-disease trade-off hypothesis.

In summary, the results of this study provide strong support for the hypothesis that prey of varying phylogenetic similarities differ in value to predators. Yet a number of issues require further clarification. One issue is the generality of these ideas. Do prey of varying phylogenetic similarities differ in value to predators in other taxa, and if so, do these predators prefer to eat phylogenetically intermediate prey? Another unresolved issue is at how fine of a genetic scale the nutrition-disease trade-off applies. Close relatives appear to be more likely than nonrelatives to exchange parasites in honey bees (Shykoff and SchmidHempel 1991) and humans (Black 1994), but the opposite holds for cannibalistic tiger salamanders (Pfennig et al. 1999). Finally, what is the relative importance of specialist versus generalist pathogens in shaping the evolution of behavior? Answers to these questions may help us unravel not only the evolution of diet choice but also how parasites influence the evolution of host behavior.

\section{Acknowledgments}

I thank R. McNatt, K. Pfennig, and A. Swei for laboratory assistance; E. Sherbrooke and W. Sherbrooke of the Southwestern Research Station (Portal, Ariz.) for furnishing housing and laboratory facilities; and B. Brodie, M. McPeek, K. Pfennig, B. Podolsky, K. Reeve, and P. Sherman for helpful commentary. I also thank the Arizona Game and Fish Department for providing collecting permits and the National Science Foundation for financial support.

\section{Literature Cited}

Alpers, M. 1987. Epidemiology and clinical aspects of kuru. Pages 451-465 in S. B. Prusiner and M. P. McKinley, eds. Prion: novel infectious pathogens causing scrapie 
and Creutzfeldt-Jakob disease. Academic Press, Orlando, Fla.

Baker, H. F., R. M. Ridley, and G. A. H. Wells. 1993. Experimental transmission of BSE and scrapie to the common marmoset. Veterinary Record 132:403-406.

Barbehenn, K. R. 1969. Host-parasite relationships and species diversity in mammals: an hypothesis. Biotropica 1:29-35.

Berg, L. J. 1994. Insights into the role of the immune system in prion diseases. Proceedings of the National Academy of Sciences of the USA 91:429-432.

Berger, J. R., E. Weisman, and B. Weisman. 1997. Creutzfeldt-Jakob disease and eating squirrel brains. Lancet 350:642.

Bilde, T., and S. Toft. 1994. Prey preference and egg production of the carabid beetle Agonum dorsale. Entomologia Experimentalis et Applicata 73:151-156.

Black, F. L. 1994. An explanation of high death rates among New World peoples when in contact with Old World diseases. Perspectives in Biology and Medicine 37: 292-307.

Boots, M. 1998. Cannibalism and the stage-dependent transmission of a viral pathogen of the Indian meal moth, Plodia interpunctella. Ecological Entomology 23: 118-122.

Brodie, E. D., Jr., D. R. Formanowicz, Jr., and E. D. Brodie III. 1978. The development of noxiousness of Bufo americanus tadpoles to aquatic insect predators. Herpetologica 34:302-306.

Bruce, M. E., R. G. Will, J. W. Ironside, I. McConnel, D. Drummond, A. Suttie, L. McCardle, et al. 1997. Transmission to mice indicate that "new variant" CJD is caused by the BSE agent. Nature (London) 389:498-501.

Burdon, J. J., and A. M. Jarosz. 1988. The ecological genetics of plant-pathogen interactions in natural communities. Philosophical Transactions of the Royal Society of London B, Biological Sciences 321:349-363.

Chapman, J. W., T. Williams, A. Escribano, P. Caballero, R. D. Cave, and D. Goulson. 1999. Age-related cannibalism and horizontal transmission of a nuclear polyhedrosis virus in larval Spodoptera frugiperda. Ecological Entomology 24:268-275.

Church, S. C., and T. N. Sherratt. 1996. The selective advantages of cannibalism in a Neotropical mosquito. Behavioral Ecology and Sociobiology 39:117-123.

Crump, M. L. 1990. Possible enhancement of growth in tadpoles through cannibalism. Copeia 1990:560-564.

- 1992. Cannibalism in amphibians. Pages 256-276 in M. A. Elgar and B. J. Crespi, eds. Cannibalism: ecology and evolution among diverse taxa. Oxford University Press, Oxford.

Daly, H. V., J. T. Doyen, and A. H. Purcell III. 1998. In- troduction to insect biology and diversity. 2d ed. Oxford University Press, New York.

Debyser, I. W. J., and P. Zwart. 1991. Review of the most important diseases in crocodylia which possibly interfere with human health. Vlaams Diergeneeskundig Tijdschrift 60:164-169.

Dhandapani, N., S. Jayaraj, and R. J. Rabindra. 1993. Cannibalism on nuclear polyhedrosis-virus infected larvae by Heliothis armigera (Hubn.) and its effect on viral-infection. Insect Science and its Applications 14: 427-430.

Dobson, A. P., P. J. Hudson, and A. M. Lyles. 1992. Macroparasites: worms and others. Pages 329-348 in M. J. Crawley, ed. Natural enemies: the population biology of predators, parasites and diseases. Blackwell Scientific, Oxford.

Eibl-Eibesfeldt, I. 1949. Über das Vorkommen von Schreckstoffen bei Erdkrötenquappen. Experientia 5: 236.

Elgar, M. A., and B. J. Crespi. 1992. Ecology and evolution of cannibalism. Pages 1-12 in M. A. Elgar and B. J. Crespi, eds. Cannibalism: ecology and evolution among diverse taxa. Oxford University Press, Oxford.

Formanowicz, D. R., Jr., and E. D. Brodie, Jr. 1982. Relative palatabilities of members of a larval amphibian community. Copeia 1982:91-97.

Foster, J. D., J. Hope, I. McConnell, M. Bruce, and H. Fraser. 1994. Transmission of bovine spongiform encephalopathy to sheep, goats, and mice. New York Academy of Sciences 724:300-303.

Fraser, H., M. E. Bruce, A. Chree, I. McConnell, and G. A. H. Wells. 1992. Transmission of bovine spongiform encephalopathy and scrapie to mice. Journal of General Virology 73:1891-1897.

Freeland, W. J. 1983. Parasites and the coexistence of animal host species. American Naturalist 121:223-236.

Gajdusek, D. C. 1977. Unconventional viruses and the origin and disappearance of kuru. Science (Washington, D.C.) 197:943-960.

Gao, F., E. Bailes, D. L. Robertson, Y. Chen, C. M. Rodenburg, S. F. Michael, L. B. Cummins, et al. 1999. Origin of HIV-1 in the chimpanzee Pan troglodytes troglodytes. Nature (London) 397:436-441.

Gibbs, C. J., H. L. Amyx, A. Bacote, C. L. Masters, and D. C. Gajdusek. 1980. Oral transmission of kuru, Creutzfeldt-Jakob disease, and scrapie to nonhumanprimates. Journal of Infectious Diseases 142:205-208.

Gosner, K. L. 1960. A simplified table for staging anuran embryos and larvae with notes on identification. Herpetologica 16:183-190.

Hegner, R. W. 1924. The relations between a carnivorous diet and mammalian infection with intestinal protozoa. American Journal of Hygiene 40:393-400. 
Hill, A. F., M. Desbruislas, S. Joiner, K. C. L. Sidle, I. Gowland, J. Collinge, and L. J. Doey. 1997. The same prion strain causes CJD and BSE. Nature (London) 389: $448-450$.

Huchzermeyer, F. W. 1997. Public health risks of ostrich and crocodile meat. Revue Scientifique et Technique de l'Office International des Epizooties 16:599-604.

Kelly, J., R. Hopkins, and M. E. Rimsza. 1995. Rattlesnake meat ingestion and Salmonella arizona infection in children: case report and review of the literature. Pediatric Infectious Disease Journal 14:320-322.

Kiesecker, J. M., D. K. Skelly, K. H. Beard, and E. Preisser. 1999. Behavioral reduction of infection risk. Proceedings of the National Academy of Sciences of the USA 96:9165-9168.

Kikuchi, K., T. Sato, T. Furuta, I. Sakaguchi, and Y. Deguchi. 1997. Use of meat and bone meal as a protein source in the diet of juvenile Japanese flounder. Fisheries Science 63:29-32.

Koralnik, I. J., E. Boeri, W. C. Saxinger, A. L. Monico, J. Fullen, A. Gessain, H. G. Guo, et al. 1994. Phylogenetic associations of human and simian T-cell leukemia/lymphotropic virus type 1 strains: evidence for interspecific transmission. Journal of Virology 68:2693-2707.

Lemon, W. C. 1991. Fitness consequences of foraging behaviour in the zebra finch. Nature (London) 352: 153-155.

Licht, L. E. 1967. Growth inhibition in crowded tadpoles: intraspecific and interspecific effects. Ecology 48: 736-745.

Lively, C. M. 1996. Host-parasite coevolution and sex. BioScience 46:107-114.

Lozano, G. A. 1991. Optimal foraging theory: a possible role for parasites. Oikos 60:391-395.

Matuschka, F. R., and B. Bannert. 1989. Recognition of cyclic transmission of Sarcocystis stehlinii n. sp. in the Gran Canarian giant lizard. Journal of Parasitology 75: 383-387.

Meffe, G. K., and M. L. Crump. 1987. Possible growth and reproductive benefits of cannibalism in the mosquitofish. American Naturalist 129:203-212.

Nagai, Y., S. Nagai, and T. Nishikawa. 1971. The nutritional efficiency of cannibalism and an artificial feed for the growth of tadpoles of Japanese Toad (Bufo vulgaris sp.). Agricultural and Biological Chemistry 35:697-703.

Nei, M. 1987. Molecular evolutionary genetics. Columbia University Press, New York.

Nengas, I., M. N. Alexis, and S. J. Davis. 1999. High inclusion levels of poultry meals and related byproducts in diets for gilthead seabream Sparus aurata L. Aquaculture 179:13-23.

Nokes, D. J. 1992. Microparasites: viruses and bacteria. Pages 349-374 in M. J. Crawley, ed. Natural enemies: the population biology of predators, parasites and diseases. Blackwell Scientific, Oxford.

Pfennig, D. W. 1992. Polyphenism in spadefoot toad tadpoles as a locally adjusted evolutionarily stable strategy. Evolution 46:1408-1420.

Pfennig, D. W., A. Mabry, and D. Orange. 1991a. Environmental causes of correlations between age and size at metamorphosis in Scaphiopus multiplicatus. Ecology 72:2240-2248.

Pfennig, D. W., M. L. G. Loeb, and J. P. Collins. $1991 b$. Pathogens as a factor limiting the spread of cannibalism in tiger salamanders. Oecologia (Berlin) 88:161-166.

Pfennig, D. W., S. Ho, and E. A. Hoffman. 1998. Pathogen transmission as a selective force against cannibalism. Animal Behaviour 55:1255-1261.

Pfennig, D. W., J. P. Collins, and R. E. Ziemba. 1999. A test of alternative hypotheses for kin recognition in cannibalistic tiger salamanders. Behavioral Ecology 10: 436-443.

Polis, G. A. 1981. The evolution and dynamics of intraspecific predation. Annual Review of Ecology and Systematics 12:225-251.

Pomeroy, L. V. 1981. Developmental polymorphism in the tadpoles of the spadefoot toad Scaphiopus multiplicatus. Ph.D. thesis, University of California, Riverside.

Prusiner, S. B. 1998. Prions. Proceedings of the National Academy of Sciences of the USA 95:13363-13383.

Richmond, N. D. 1947. Life history of Scaphiopus holbrookii holbrookii (Harlan). I. Larval development and behavior. Ecology 28:53-67.

Sattler, P. W. 1980. Genetic relationships among selected species of North American Scaphiopus. Copeia 1980: 605-610.

Schaub, G. A., C. A. Böker, C. Jensen, and D. Reduth. 1989. Cannibalism and coprophagy are modes of transmission of Blastocrithidia triatomae (Trypanosomatidae) between triatomines. Journal of Protozoology 36: 171-175.

Sherman, P. W., H. K. Reeve, and D. W. Pfennig. 1997. Recognition systems. Pages 69-96 in J. R. Krebs and N. B. Davies, eds. Behavioural ecology: an evolutionary approach. 4th ed. Blackwell Scientific, Oxford.

Shykoff, J. A., and P. S. Schmid-Hempel. 1991. Parasites and the advantage of genetic variability within social insect colonies. Proceedings of the Royal Society of London B, Biological Sciences 243:55-58.

Stebbins, R. C. 1985. A field guide to western reptiles and amphibians. 2d ed. Houghton Mifflin, Boston.

Stephens, D. W., and J. R. Krebs. 1986. Foraging theory. Princeton University Press, Princeton, N.J.

Toft, S., and D. H. Wise. 1999. Growth, development, and survival of a generalist predator fed single- and mixed- 
species diets of different quality. Oecologia (Berlin) 119: 191-197.

Vasconcelos, S. D., T. Williams, R. S. Hails, and J. S. Cory. 1996. Prey selection and baculovirus dissemination by carabid predators of Lepidoptera. Ecological Entomology 21:98-104.

Voevodin, A., B. K. Johnson, E. T. Samilchuk, G. A. Stone, R. Druilhet, W. J. Greer, and C. J. Gibbs, Jr. 1997. Phylogenetic analysis of simian T-lymphotropic virus type 1 (HTLV-1) in common chimpanzees (Pan troglodytes): evidence for interspecies transmission of the virus between chimpanzees and humans in central Africa. Virology 238:212-220.
Waldman, B. 1981. Sibling recognition in toad tadpoles: the role of experience. Zeitshrift für Tierpsychologie 56: 341-358.

Wildy, E. L., D. P. Chivers, J. M. Kiesecker, A. R. Blaustein. 1998. Cannibalism enhances growth in larval long-toed salamanders (Ambystoma macrodactylum). Journal of Herpetology 32:286-289.

Worthylake, K. M., and P. Hovingh. 1989. Mass mortality of salamanders (Ambystoma tigrinum) by bacteria (Acinetobacter) in an oligotrophic seepage mountain lake. Great Basin Naturalist 49:364-372.

Associate Editor: Mark A. McPeek 